\title{
PENSAMENTO, FENÔMENO EXPERIMENTAL E EXPERIMENTO NA PROPOSTA PRAGMATICISTA*
}

\author{
Lauro Frederico Barbosa da SIL.VIIRA ***
}

\begin{abstract}
RESUMO: O Pragmaticismo de Charles Sanders Peirce. como teoria geral da concencian, é luma teoria do signo e uma teoria do pensamento. Limitando-se à comsideraçào do "teor racional" dos simbolos, o pragmaticismo procura estabelecer o tipo de causaçào atribuivel ac nensamento: sação eficiente centralizada na percepçào e no experimento e uma causaçăo final que determina um!n habito racional de conduta diante da classe geral de fenomenos experimentais representada ino conceito).
\end{abstract}

UNITERMOS: Pragmaticismo; pensamento; fenömeno experimental; experimemto; semiotica; simbolo; concepção.

Em 1905, Charles Sanders Peirce (1839-1914) já na fase mais madura de seu pensamento filosófico, propõe desenvolver a teoria de que ... "uma conceénçüo, isto é, o teor (conteúdo significativo) racional de uma palavra ou outra expressào, reside exclusivamente em sua concebivel influência sobre a conduta da vida; de modo que, já qué obviamente nada que não possa resultar de um experimento pode exereer qualquer influência direta sobre a conduta, se se puder definir acuradamente todos os fenomenos experimentais concebiveis que a afirmação ou a negação (rejecçào) de um conccito poderiam implicar, ter-se-á aí a definição completa do conceito, e nele năo há absolutamente nada mais. (4, v. 5, 412; os grifos sào do autor).

Em primeiro lugar, cabe notar yue a proposta peirceana é a elaboraçào de uma teoria da concepção de uma palavra ou de uma outra expressão.

No inte: ior do pensamento peirceano uma teoria constitui-se numa argumentaçào dedutiva que desdobra, com rigor lógico, as implicações contidas numa hipótese inicial. Mantém o caráter conjectural logicamente possivel que caracteriza a hipótese, permitindo por seu desdobramento, o estabelecimento das condições de experimentação que indutivamente, no decorrer da experiência, irá verificar sua adequação ao real. Tal adequação constituir-se-á, precipuamente, no estabelecimento do grau probabilistico de freqüência em que a hipótese se adequará aos fatos da experiência (a).

O que se tem, portanto, no enunciado é uma construçào hipotética, à qual se seguirá um discurso dedutivo.

\footnotetext{
* Este texto constitui a redação revista, ampliada c acrescida de notas, da aula proficrida pelo autor uo (ontcurso publico pa

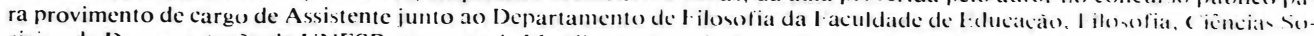
ciais e da Documentaçào da UNESP. (ampus de Marilia, na átca de Semiotica. no dia 20 de matso de 19st.

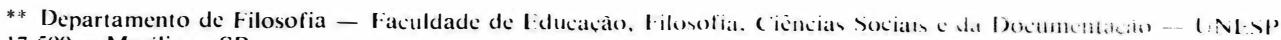
$17.5(0)$ - Marilia - SP.
} 
SILVEIRA, L.F.B. da - Pensamento, fenômeno experimental e experimento na proposta pragmaticista.

Trans/Form/Ação, São Paulo, 7:49-59, 1984.

Subjacente ao texto, encontra-se a concepção de signo para Peirce e a identificação deste com o pensamento. O pensamento, por sua vez, é aceito como ação e como produto - em suma, como semeiose (b) — de uma inteligência “científica": aquela que é capaz de aprender com a experiência, aquela que pensa no tempo. (cf. 4, v. 3, 227). (c)

O signo - ou representamen —, resumidamente, é alguma coisa que pode estar no lugar de uma outra (seu objeto) determinando uma idéia interpretante dessa relação. O objeto determina a relação do signo para com ele e, da relação assim estabelecida, decorre a determinação da idéia interpretante. (d)

A idéia interpretante é da natureza do signo, e o objeto, na rede triádica relacional, constitui-se igualmente em signos. (e)

Pensar é, fundamentalmente, interpretar as relações semióticas e desse modo produzir seus próprios signos.

Toda consideração do pensamento manterá necessarimente, na proposição peirceana, relação estreita com a correlação semiótica e explorará o diagrama fundamental desta última.

Seja qual for a consideração do universo da significação, e a investigação no interior do universo dos signos, tanto uma quanto a outra terão por referência necessária o pensamento, e constituir-se-ão numa investigação do próprio pensamento.

A teoria da concepção apresenta, portanto, essa dupla dimensão: é uma teoria do signo e uma teoria do pensamento; é uma semiótica e uma teoria da conduta racional.

Parece pois que a articulação básica da hipótese sobre a qual Peirce pretende teorizar, constitui-se exatamente naquela que vincula produção do signo e conduta racional.

Deve-se notar que no vasto domínio aberto pela semiótica e por uma teoria do pensamento, um recorte é realizado pela hipótese em consideração - a restrição da classe de signos a ser estudada e do fundamento ou aspecto pelo qual tais signos serão considerados: o 'teor racional', ou o 'conteúdo significativo racional' - como parece mais proximamente traduzir-se 'the rational purport' - 'de uma palavra ou repressão’, já inicialmente dirige a atenção do filósofo para um subconjunto bastante determinado de signos.

Desenvolver-se-ão as relações determinantes do símbolo (cf. 4, v. 2, 247; 254; 264; 265-273) como signo de natureza convencional, determinado por classes gerais de objetos e determinando, por sua vez, hábitos gerais de conduta. Importa aqui, por conseguinte, o signo em sua forma mais genuina, em sua mais plena generalidade. (f)

No mesmo artigo em que Peirce apresenta a hipótese central de sua teoria, respondendo à objeção que faltam ao experimentalista - tipo de investigador com o qual Peirce se identifica — os méritos do bom observador que deseja pela história natural entrar num contacto apaixonado com a natureza e cantar... " no glorioso órgão da observação, os tesouros que só a ele a natureza confia' '..., confirma o caráter seletivo da operação que, em outro texto (cf. 4, v. 2, 227) denomina observação abstrativa. Reconhece com o objetante que a riqueza (o grifo é do autor) dos fenômenos encontra-se em sua qualidade sensual, mas que não é a exploração dessa dimensão que a teoria que propõe - o pragmaticismo - pretende empreender.

“'O pragmaticismo, diz o texto (4, v. 5, 428), não pretende definir os equivalentes fenomenais das palavras e das idéias gerais, mas, ao contrário, elimina seu elemento sensual e se esforça em definir o conteúdo significativo racional, e este ele encontra no procedimento intencional (ou talvez, utilitário) (o parêntese é do tradutor e se refere à tradução de "'purposive bearing'”) da palavra ou da proposição em questão...', 
SILVEIRA, L.F.B. da - Pensamento, fenômeno experimental e experimento na proposta pragmaticista.

Trans/Form/Ação, São Paulo, 7:49-59, 1984.

E que é sempre o caráter geral da palavra ou da proposição que se procura investigar e estabelecer, reafirma o autor quando questionado sobre a postura a ser tomada diante dos nomes próprios (4, v. 5, 429). (g)

A esse caráter geral e intencional do símbolo, Peirce denomina concepção. Eis a tese do texto: "a concepção reside exclusivamente em sua concebível influência sobre a conduta da vida.",

A seqüência do texto e sua dimensão estratégica consistem em estabelecer como o geral exerce uma causação real. Duas correlações se apresentam e seu conjunto perfaz a especificidade dessa causação.

De um lado, a relação eficiente; de outro, a relação final. O símbolo realizando aí o papel de mediador genuíno dessas duas vertentes.

Da parte da causação eficiente, declara Peirce sob a forma de um pressuposto:

..." somente o que pode resultar de um experimento pode exercer qualquer influência sobre a conduta da vida',

A fatualidade, o confronto ef etivo com o outro, é condição necessária para a modificação da conduta. A modificação efetiva da conduta supõe em sua raiz a particularidade de experimento. A modificação da conduta será real somente ao se constituir num fato consumado. Antes, é uma potencialidade que meramente pode realizar-se.

A conduta da vida, no entanto, não é uma mera sucessão desconexa de fatos consumados, ela se constitui numa continuidade. O experimento, interagente com a conduta, é um fato, mas integra um universo fenomenológico. A percepção do fato possibilita tal integração, pois, ao ser percebido ele é recebido como idealmente possível e, na ocasião, tomado como real. (cf. 1, v. 8, 148). Baseando-se principalmente no texto de Peirce, "Introduction to the Logic of Quantity"' (4, v.3, 526-552), datado de 1897, Sandra B. Rosenthal (5, p. 15-22) esclarece esse estatuto do Fato no interior do universo fenomenológico - no interior do mundo:

“Um mundo é, por definição, consistente porque um mundo é o conteúdo concreto que é delineado por um conjunto de proposições consistentes. O mundo responde às leis do terceiro excluído e da contradição (não sendo, diríamos com Peirce, nem vago nem indeterminado) e assim representa o ideal do que foi conceitualmente articulado - e desse modo tornado preciso a seu limite ideal. "O mundo', portanto, é a um tempo a base para toda experiência e o ideal de uma sintese completa da experiência possivel. Talvez seja possivel dizer, metaforicamente, que enquanto a realizada é a infinitude de um processo contínuo ou em avanço, o mundo é a fixação lógica de um número infinito de cortes possíveis no seu interior. O mundo, então, é o contexto de significado no interior do qual todos os outros quadros e objetos podem ser articulados no sentido em que o mundo é o "mais amplo" conteúdo (content) ou a moldura envolvente da referência da aplicação e de um conjunto de estruturas significativas relativas ao independentemente real e, portanto, das proposições que podem delinear a experiência consistentemente dentro do contexto desses significados. Tal mundo, pois, abre em uma direção para as estruturas do independentemente real e para as possibilidades que ele apresenta e, em outra direção, para a estrutura de modos de apreender a independentemente real e para as possibilidades que tais modos de apreender permitem.' (5, p. 19). (h).

A noção de fato nos textos peirceanos dedicados à Fenomenologia ou Faneroscopia que instauram as categorias denominadas pelo autor, coenopithagóricas, é caracterizada pela força bruta (cf. 4, v. 1, 322 - 325; v.5, 45-58; 1, v.8. 265-266, 330-332), sofre no texto que está sendo analisado uma modificação devido à sua inserção pressuposta no universo da experiência. O universo da experiência, por sua vez, torna-se 
SILVEIRA, L.F.B. da - Pensamento, fenômeno experimental e experimento na proposta pragmaticista. Trans/Form/Ação, Sào Paulo, 7:49-59, 1984.

possivel para a consciência quando, na percepção, apresenta-se consistente com o universo ligicamente possível.

Tal como o mundo se distingue do independentemente real, o fato distinguir-se-á, sem se ver destituido de seu aspecto "hic et nunc" da mera ocorrência. Tal distinção não é uma elaboração feita por conta da ilustre intérprete do pensamento peirceano; esta a encontra num texto que não integra os Collected Papers. Na The Microfilm Edition of the Peirce Papers (Section 647, p.8), Sandra Rosenthal lê a seguinte passagem do autor:

“Preciso em primeiro lugar estabelecer a distinção entre um fato e o que em outras conexões é freqüentemente chamado um Evento mas que, devido ao fato desta palavra ser usada na Doctrine of Chances num sentido mais estrito... deve aqui ser denominado uma Ocorrência. Uma Ocorrência, a qual o Pensamento analisa em Coisas e Acontecimentos, é necessariamente Real; mas ela não pode nunca ser conhecida ou mesmo imaginada em todos os seus infinitos detalhes. Um fato, por outro lado, pertence ao Universo real na medida em que pode ser representado numa Proposição, e em vez de ser, tal como uma Ocorrência, uma fatia do Universo, deve mais ser comparado a um principio químico extraído pela força do Pensamento; e embora ele seja ou possa ser Real, ainda em sua existência Real está inseparavelmente combinado com um enxame infinito de circunstâncias que não fazem parte do pı́prio Fátó. É imipossível traçar nosso caminho através do intrincado lógico do ser se não mantivermos em nossos Pensamentos, nitidamente separadas, essas duas coisas: a Ocorrência e o Fato Real.' (5, p. $16-17)$. (Os grifos e as maiúsculas obedecem à apresentação do texto no artigo citado e certamente encontram-se no original do autor).

O experimento, capaz de modificar a conduta, está por sua vez centrado no fato e $\mathrm{o}$ excede; o fato interagente e percebido é índice do real no universo fenomênico. Consistente com o mundo lógico, ele dá concretude ao pensamento, conectando-o com os demais componentes do mundo do fenômeno.

Desse modo torna-se mais clara a decomposição do experimento realizada por Peirce na resposta a uma das objeçòes de What Pragmatism is (4, v. 5, 424), onde se acentua o lugar do ato no interior do complexo do experimento e a distinção sutil, mas fundamental, entre experimento e evento:

Primeiramente, os experimentos, diferentemente do que parecia supor o objetante - certamente o senso comum e mais de um posicionamento filosófico - não são isolados uns dos outros, são componiveis, compostos e se desenvolvem no tempo guardando sua identidade.

Em segundo lugar, o experimento estrutura-se de maneira bipolar, tensionado em seus elementos essenciais pela representação e pela interação com o universo exterior (ou quase - exterior) numa constante passagem de um polo ao outro. Peirce insiste nesta polarização e seu texto merece ser lido integralmente; alguns comentários sendo intercalados, recorrendo-se então ao uso de parênteses.

“Quais são os ingredientes essenciais de um experimento? Em primeiro lugar, naturalmente, um experimentador de carne e osso (de carne e sangue, no texto original). Em segundo lugar, uma hipótese verificável. Tal hipótese é uma proposição relacionada ao universo que envolve o experimentador, ou alguma parte bem conhecida desse universo, afirmando ou negando dele somente alguma possibilidade ou impossibilidade experimental.

O terceiro ingrediente é uma dúvida sincera na mente do experimentador sobre a verdade daquela hipótese.

Passando por cima cle vários ingredientes nos quais não precisamos nos deter... (seria, cabe notar, fundamental deter-se nesses ingredientes caso se tratasse de analisar 
SILVEIRA, L.F.B. da - Pensamento, fenômeno experimental e experimento na proposta pragmaticista.

Trans/form/Ação, Sào Paulo, 7:49-59, 1984.

os elementos generalizadores)..., - o propósito, o plano e a resolução - , chegamos ao ato de escolha pelo qual o experimentador isola (singulariza) certos objetos identificáveis sobre os quais operar. (Tais elementos, objetos de escolha e exemplificação são fatos pertinentes ao mundo do real e submissos ao mundo ideal das possibilidades).

Em seguida... (e ai se encontra o vórtice da singularização fatual)... dá-se o ATO (em letras maiúsculas nos`Collected Papers) pelo qual o experimentador modifica aqueles objetos. Depois chega a reação subseqüente do mundo sobre o experimentador em uma percepção... (trata-se pois da reação percebida enquanto tal. A palavra reação está sublinhada no texto do autor)... e finalmente o reconhecimento do ensinamento do experimento.' $(4, v .5,424)$.

O caráter conectivo do experimento - do pensamento e da ação física com o mundo - fica mais claro ainda quando Peirce distribui para cada polo, os ingredientes do experimento: experimento e evento nitidamente se distinguem e, se for aceito o texto citado por Sandra Rosenthal, também Fato e Evento (ou Ocorrência).

Assim, na continuação do texto, pode-se ler:

"Enquanto as duas principais partes do evento propriamente dito são a ação e a reação, a unidade de essência do experimento (... sua participação no mundo intencional, geral semiótico, diríamos - , pois unidade de uma pluralidade...) encontra-se em seu propósito e em seu plano, aqueles elementos sobre os quais passou-se por cima na enumeração. (Elementos estes que desdobram dedutivamente a hipótese).' (4, 1.5. 424).

Por sua especificidade, o experimento modifica ef icientemente a conduta cobrando dela um novo posicionamento que interprete sua referência à realidade. A realidade referida é aquela que indicialmente, existentemente, se impôs à consideração.

Pesa agora, em especial, a causaçào final, interpretante e terceiro correlato do signo.

"Se se puder definir acuradamente todos os fenômenos experimentais concebíveis que afirmação ou a negação (rejeição) de um conceito poderiam implicar, ter-se-ia aí definição completa do conceito...',

Em sua forma hipotética, o conceito chega à conduta da vida, ao contínuo da experiência racional, pelo experimento por ela designado. O experimento, por sua vez, implica a interação experimentador - mundo. O evento integrado no experimento é um exemplo do objeto (geral) representado no símbolo hipotético.

O conceito que pretende Peirce teorizar, é o "medium' que transforma o mero evento no objeto de uma conduta racional, ou seja, de um processo contínuo e generalizante, autoconsciente e autocontrolado - em suma - no objeto de um hábito racional. (c.f. 4, v.5, $417-420,427,476-487$ ).

Isto se faz na medida em que o experimento, representado no conceito, é tomado como concretização de uma classe geral de fenômenos experimentais à qual pertence.

A concepção explicita a inserção possível dos experimentos na regularidade de um mundo imerso no acaso mas pertinente ao domínio da lei e do pensamento.

Se for possivel prever as reaçōes do mundo diante de determinadas circunstâncias experimentais ou suas futuras interaçòes com o experimentador, mesmo que certas particularidades do evento escapem a tal previsão, a conduta diante do mundo emergirá do universo do imprevisível.

Por esse ato judicativo concernente às relações entre as condiçōes de experimentação e suas consequências todas vez que tais condiçōes se ef etivarem, ao menos numa freqüência calculável, a conduta da vida tornar-se-á mais preparada para confrontar-se com o mundo e para procurar com efetiva esperança de sucesso, os objetos que elegeu como um fim. 
SILVEIRA, L.F.B. da - Pensamento, fenômeno experimental e experimento na proposta pragmaticista. Trans/Form/Ação, São Paulo, 7:49-59, 1984.

Interiorizadas essas correlações sob forma de hábitos, mediante a ação dos símbolos, a conduta cresce em sua integração com o mundo, ef etiva sua racionalidade e contribui para a concreção crescente da racionalidade do próprio mundo a que pertence.

Esse é o trabalho da ciência, a ética da conduta racional, o dever ser da conduta da vida e o objeto da teoria que Peirce pretendeu desenvolver sob a denominação de Pragmaticismo.

Voltando-se intrinsecamente para o futuro que caracteriza as relações gerais, completa-se assim a dupla causação da teoria da concepção.

Em resposta ao objetante que pretendia encontrar no pragmaticismo uma doutrina redutora do pensamento à ação, Peirce encontra ocasião para explicitar mais o caráter geral e contínuo do processo do pensamento e do hábito dele decorrente.

..."O pragmaticista, diz o texto, não faz com que o summum bonum consista na ação, mas faz com que consista naquele processo de evolução pelo qual o existente chega a incorporar cada vez mais aqueles gerais dos quais dizia-se ainda há pouco estarem destinados (i), que é o que procuramos expressar chamando-os razoáveis. Em seus mais elevados estágios, a evolução se efetiva cada vez mais amplamente através do autocontrole, e isto parece ao pragmaticista uma espécie de justificativa para tornar geral o conteúdo significativo racional' '... (4, v.5, 433).

Se o fim último procurado, a maior perfeição do pensamento, não é a particularidade da ação - e toda ação de um pensamento que interage com o mundo é particular - mas um crescimento contínuo evolutivo, a mediação do signo, e em especial do conceito como signo genuinamente geral, é condição indispensável para sua ef etivação. Dada essa generalidade intrínseca máxima do pensamento conceitual, o hábito por ele determinado é o maior bem que o pensamento pode alcançar.

Um texto como esse último é certamente suficiente para apresentar o hábito racional como o summum bonum do pensamento. Peirce contudo, já tinha encontrado anteriormente ocasião de melhor explicitar o que espera a Razão como sua mais perf eita realização. Dado o caráter genuinamente geral e dinâmico de sua atividade, Peirce rejeita numa conferência em 1902 (4, v. 1, 591-615) que o ideal da conduta racional possa ser algo utilitário, uma mera sensação ou algo estático.

Após uma longa exposição, o autor alcança a caracterização precisa de que pode ser o ideal último da Razão, seu summum bonum.

“'O próprio do Geral, da Razão, consiste em governar os eventos individuais. Desse modo, portanto, a essência da Razão é tal que seu ser jamais estará completamente acabado (perfeito).

Ela sempre deve estar num estado de incipiência, de crescimento. Isto assemelhase ao caráter de um homem o qual consiste nas idéias que ele conceberá e nos esforços que ele fará, e que só se desenvolve quando as ocasiões de fato aparecem. E ainda mais, durante toda sua vida nenhum filho de Adão manifestou plenamente o que havia em seu interior. Desse modo, o desenvolvimento da Razão requer como uma parte, mais eventos individuais do que jamais poderá ocorrer. Requer, também, todo o colorido de todas as qualidades de sentimento, incluindo o prazer no seu lugar próprio dentro do conjunto. Este desenvolvimento da Razão consiste, será possível observar, na incorporação, isto é, na manifestação. A criação do universo, que não se deu numa certa semana atarefada, no ano 4004 a.C., mas que está se encaminhando hoje e nunca estará acabada, é o próprio desenvolvimento da Razão. Não vejo como é possível ter-se um ideal mais satisfatório do admirável do que o desenvolvimento da Razão assim compreendido. A única coisa que não é devida a uma razão interior é a própria Razão compreendida em sua plenitude, enquanto nos for possível compreendê-la. Segundo esta concepção, o ideal de conduta será executar nossa pequena função na operação da criação 
SILVEIRA, L.F.B. da - Pensamento, fenômeno experimental e experimento na proposta pragmaticista. Trans/Form/Ação, São Paulo, 7:49-59, 1984.

dando uma mão para tornar o mundo mais razoável do que nunca, e, como diz a gíria, ele está “prontinho'” para que assim façamos”' $(4, v .1,615)$.

É possível existir dimensões da Razão que o pragmaticismo não pretenda teorizar. Esta exclusão parece confirmar-se quando o autor declara limitar ao conceitual o domínio de investigação. Por outro lado, no entanto, o cume da racionalidade está no pensamento dotado de plena generalidade.

Aparentemente um texto como o Ideals of Conduct parece fazer exceder ao escopo da proposta pragmaticista o summum bonum da Razão, mas é somente o exercício da atividade mais alta da racionalidade que poderá, incorporando-se, elevar as diversas outras qualidades que a integram.

O pragmaticismo, poder-se-ia concluir, é uma doutrina do summum bonum racional e o prosseguimento do texto dos Ideals of Conduct, se bem que truncado na edição dos Collected Papers, parece vir plenamente de encontro com essa conclusão e reconhecer, ao nível do raciocínio - e, consequentemente, do conceitual - a caracterização do ideal racional como sendo a proposta do pragmaticismo: "Na lógica, observarse-á que o conhecimento é racionalidade; e o ideal do raciocínio será seguir os métodos que farão com que o pensamento se desenvolva o mais rapidamente possível' '... (4, $v$. $1,615)$.

Se o texto de What Pragmatism is, que foi tomado desde início como objeto de leitura, caracteriza-se como um programa de investigação, ele mesmo exige ser explorado em suas implicações para fazer surgir, ao menos parcialmente, sua potencialidade. Peirce foi o primeiro a proceder dessa maneira e, no artigo em que expõe o enunciado da teoria, já deixa entrever como esta é capaz de enfrentar as dificuldades que sua problemátiça suscita. Outros escritos se seguiram nos quais pacientemente foram desdobradas as partes fundamentais do conceito e da conduta racional. Um texto como Ideals of Conduct precede à formulação em questão mas tão claramente prepara seu surgimento, que tem sua longa argumentação retomada e resumida em parágrafos posteriores de What Pragmatism is, quando, por exemplo, se trata de estabelecer a ética da conduta racional (cf. 4, v.5, 418-419).

Colocar como horizonte mais largo o processo evolutivo da razão no cosmos para a proposta pragmaticista e aí inserir a meta última da conduta científica, parece encontrar legitimação não só no desenvolver do What Pragmatism is mas no conjunto da obra de Peirce, contemporânea ao texto. Ao afirmar, pois, que estabelecida sua definição segundo as prescrições da proposta teórica que acaba de enunciar, no conceito... “ "não há absolutamente nada mais", sublinhando a asserção para mais enfatizá-la, o autor estende a dimensões cósmicas e até ao summum bonum da Razão as conseqüências do pensamento científico, aquele que é capaz de aprender com a experiência. (cf. 4, v. 227).

\section{NOTAS}

a) Teoria para Peirce é um procedimento racional com características bastante determinadas. Em 1878 (cf. 4. v.2.636-640), ela se coloca em continuidade com o levantamento das correlações hipoteticamente estabelecidas pela observação mas acrescenta uma explicação, igualmente hipotética, dos desvios das fórmulas de correlação. Em 1897 (cf. 4v. 3.516), ateorização é vista como o procedimento inverso à generalização: enquanto a generalização atribui o predicado observado numa amostra à totalidade da classe a que pertence a amostra a teorização decorre da necessidade de sintetizar uma multidão de predicados num único conceito. O trabalho do pensamento hipotético, denominado abdutivo ou retrodutivo, a construção de dia- 
SILVEIRA, L.F.B. da - Pensamento, fenômeno experimental e experimento na proposta pragmaticista.

Trans/Form/Ação, São Paulo, 7:49-59, 1984.

gramas pela dedução e a verificação nos fatos das freqüiências da efetivação das correlaçooes deduzidas das hipóteses caracteriza a teoria nos textos peirceanos do início do século XX. Pode-se conferir esse último encaminhamento nas seguintes passagens: em 1901, 1, v. 7,220 ss; em 1902, 4, v. 2,1 - 17; em 1905, 4, v., 5,145, c, em 1905, 1,v. 8, 209. O texto em apreciação no presente artigo insere-se pois, com certeza, no quadro aqui exposto da concepção peirceana de teoria.

b) Em 1906, no texto intitulado A Survey of Pragmaticism (4, v.5,484), Peirce conceitua "semiosis" como sendo .... "uma ação, ou influência, que é, ou envolve, a cooperação de três sujeitos (o grifo é do autor), tal como um signo, seu objeto, e seu interpretante, esta tri-relativa influência não sendo de maneira alguma resolúvel em açōes entre pares. Semeiosis (em caracteres gregos no original), em grego do período romano, desde ao menos a época de Cícero, se lembro-me bem, significa a ação de praticamente toda espécie de signo; e minha definição confere a tudo que age dessa maneira o título de um "signo"... Para uma informação mais ampla sobre "semeiosis" e suas implicaçōes, conferir em Methods for Attaining Truth, em 1898, uma formulação que parece implicar o referido conceito, embora não o mencione explicitamente (cf. 4, v.5, 594), e no A Survey of Pragmaticism, já mencionado, a irredutibilidade da triadicidade da "semiosis" e a importância fundamental do elemento mediador da triáde. (cf. 4, v.5, 473). Recorrer também ao artigo de T.L.SHORT, Semiosis and Intentionality(8).

c) Quanto à relação entre "ser capaz de aprender com a experiência" e "pensar no tempo", verificar as consideraçōes elaboradas pelo autor do presente artigo em Semiótica Peirceana e Produção Poética (7).

d) Entre diversas ocasiões em que Peirce conceitua signo estabelecendo as relações aqui sumarizadas, conferir: 1897 (4, v.2, 228) - “Um signo, ou representamen, é alguma coisa que se coloca para alguém no lugar de alguma coisa por algum caráter ou capacidade. Dirige-se a alguém, isto é, cria na mente daquela pessoa um signo equivalente, ou talvez um signo mais desenvolvido. Esse signo que ele cria, eu denomino o interpretante do primeiro signo. O signo coloca-se no lugar de alguma coisa, seu objeto. Ele se coloca em lugar daquele objeto, não sob todos os aspectos (ou caracteres) mas com referência a uma espécie de Idéia, à qual algums vezes denominei o fundainento do representamen..."

1903 (4,v. 1, 539) - "Um Representamen é um sujeito de uma relação triádica a um segundo, chamado seu objeto, para um terceiro, chamado seu Interpretante, essa relação triádica sendo tal que o Representamen determina seu interpretante a colocar-se na mesma relação triádica para com o mesmo objeto para algum interpretante',

Paralelamente a este texto, embora mais analítico, conferir, de 1902 (4, v.2, 274).

$1906(4, v .4,531)$ - "A essência do signo... alguma coisa que, sendo determinada por um objeto, determina uma interpretação afim de que ela seja determinada, através dele, pelo mesmo objeto...",

De 1910, conferir (4, v.230-232).

Antes da formulação definitiva do quadro categorial peirceano e mesmo das noções de Representamen, Objeto e Interpretante - o.que só se dará a partir de 1870), a estrutura triádica do signo pode ser encontrada no On the New List of Categories (1867) sob a formulação:

“A concepção de um terceiro é a de um objeto que é de tal maneira reiacionado a dois outros, que um deles deve ser relacionado ao outro do mesmo modo com que o terceiro é relacionado àquele outro. Ora isso coincide com a concepção de um interpretante. Um Outro é plenamente equivalente a um correlato. A concepção de segundo di- 
SII VIIRA, L.F.B. da - Pensamento, fenomeno experimental e experimento na proposta pragmaticista. Trans/Form/Ação, Sào Paulo, 7:49-59, 1984.

fere da de outro, ao implicar a possibilidade de um terceiro. Seguindo a mesma linha de pensamento, a concepção de "si mesmo" (self), implica a possibilidade de um outro. O fundamento é o "si-mesmo", abstraido da concretude que implica a possibilidade de um outro..." (4, v. 1,556)

Quanto às modificações ocorridas na concepção de signo no decorrer da obra de Peirce, consultar o artigo de David SAVAN, - Questions Concernig Certain Classifications Claimed for Sign. (6).

e) Para a compreensão mais completa do estatuto dos interpretantes e dos objetos do signo, convém estabelecer a distinção entre objeto imediato e objeto dinâmico do signo e entre as duas tricotomias de interpretantes, quer no interior de cada uma delas quer nas relações entre ambas. O objeto, na medida em que integra a correlação triádica, é o objeto imediato. O objeto que é responsável pelo grau de realidade do referente (ou relacionado) da relação semiótica e pela ancoragem do signo no real, ou objeto dinâmico, só pode ser apreendido por relação colateral ao signo. Essa colateralidade não implica, contudo, que como percepto, o objeto não venha a se apresentar semioticamente. (cf. 1906 - 4,v.4, 536-539; Letter to Lady Welby, 1908 Dec. 23, 3, p. 80-83).

Quanto ao estatuto semiótico do interpretante, seja ele um sentimento (interpretante emocional), uma ação (interpretante energético) ou seja uma lei interpretante lógico e apresentando-se potencialmente (interpretante imediato), atualmente (interpretante dinâmico) ou tendencialmente (interpretante final) è mais claro que se insere no domínio do signo. Somente a inserção do interpretante último no domínio do signo aqui considerado deveria ser excluida. O interpretante último, com efeito, é o responsável último pela verdade do signo e, se pertencesse a este do mesmo modo como os outros pertencem, ou seja, articulado no continuo do processo triádico, determinaria interpretantes subseqüentes, e isto ad infinitum, contradizendo sua função precipua de ser último. A ele Peirce propõe o estatuto de mudança de hábito. (cf. 8, p.209 e 4, v.5, 473 ss).

f) Convém lembrar que o universo estritamente simbólico ou conceitual não preenche necessariamente para Peirce os aspectos mais importantes da vida. A longa conferência de 1898 sobre Vitally Important Topics (4, v.1,616-677) parece exatamente estabelecer a pouca utilidade do pensamento teórico, estritamente conceitual, para a conservação da vida. Esta seria devida quase totalmente ao instinto herdado da espécie e à sua expressão no sentimento. O texto chega a afirmar que: "A teoria é aplicável a assuntos práticos menores, enquanto que questões da importância vital devem ser deixadas ao sentimento, isto é, ao instinto' $(4, v .1,637)$.

g) Em resposta à objeção que diante da proposta pragmaticista de somente abordar os signos em sua generalidade, questiona o filósofo de como seriam enfrentados os nomes próprios, os únicos nomes que, subentende-se, designam adequadamente os indivíduos em sua individualidade, ou seja, os únicos existentes reais. Peirce explicita que os nomes próprios, diferentemente dos conceitos gerais, não estão no centro da investigação pragmaticista. Não há, no entanto, uma exclusão completa dos nomes próprios da teoria proposta, pois diferentemente do que o objetante quer levar a entender, tais nomes, enquanto palavras, são dotadas de uma certa generalidade. Um nome próprio não é ele mesmo uma coisa existente, pois permanece o mesmo seja falado ou escrito e quantas vezes aparecer. Ele é um tipo, ou forma, ao qual os objetos designados podem se conformar (o grifo é do autor) mas não podem exatamente ser e, diríamos, coincidir existencialmente. Os nomes próprios seriam, no dizer de Peirce, dotados de generalidade subjetiva ( $\approx f .4, v .5,429$ ) 
Quanto à distinção, em Peirce, entre Type e Token, ou seja, entre o signo e sua instanciação ou realização particular (sinsigno) cf. 4, v.4, 537, texto datado de 1906.

h) O mundo, como circunstante mais próximo ou mais longínquo, integra-se na relação semiótica como Objeto Dinâmico. Identificado como Universo (cf. 4, v.4, $552 \mathrm{n}, 553 \mathrm{n} 2$; v.5, 152, 506, 543), deu origem a interpretações que o despojaram de qualquer interesse mais relevante para a análise do signo (cf. 9, p.205 e 2, p.65 ss e $71 \mathrm{ss})$. Muito mais em conformidade com o pensamento peirceano, parece colocarse a perspectiva de conferir ao universo ao qual o Objeto Dinâmico se identificaria, a significação de contexto empírico onde o signo e seu interpretante atuam e que, através da relação colateral que o caracteriza, dá realidade experiencial ao que é denotado pelo signo (cf. 6, p.191-194).

i) O texto referido é o seguinte: “Assim como a conduta controlada pela razão ética tende a firmar certos hábitos de conduta, a natureza dos gerais (desde que por ela se entendam hábitos pacíficos e não contenciosos) não depende de qualquer circunstância acidental, e que nesse sentido pode ser dita destinada; também, o pensamento, controlado por uma lógica experimental racional, tende à fixação de certas opiniões, igualmente destinadas, cuja natureza será finalmente a mesma, embora a perversidade de pensamento de gerações inteiras possam causar o adiamento da fixação última' ' 4 , v.5, 430). Acentua-se assim a realidade da causação determinante dos interpretantes lógico e final do conceito e sua futura tendência de efetivar, no hábito geral, o interpretante último. Notam-se também as dimensões do propalado "otimismo" peirceano. Peirce confia na potencialidade do pensamento pois o vê integrado ao processo evolucionário dos cosmos e na conseqüente força direcional para a verdade que a experiência atualiza. Quanto, no entanto, a qualquer otimismo face aos himens e aos atos de pensar em sua particularidade, Peirce guarda, não um pessimismo, mas uma visão crítica decorrente de uma experiência histórica e, sobretudo, de uma concepção de que o contínuo evolucionário, necessariamente geral, é o detentor de toda a potência direcional face ao fim, não cabendo a qualquer particularidade individual, ou à mera somatória, dar sentido a um processo. A individualidade, no mundo fenomênico, dá atualidade ao geral, mas enquanto tal é mera negação. Assim, "as circustâncias acidentais" são intrinsecamente incapazes de determinar a natureza dos hábitos de conduta adequados e destinados ao fim último e "a perversidade do pensamento de gerações inteiras" não pode desviar o destino do pensamento em se fixar em hábitos gerais como suas instâncias últimas; podem tão somente postergar a atualização de tal destino. 
SILVEIRA, L.F.B. da - Pensamento, fenômeno experimental e experimento na proposta pragmaticista. Trans/Form/Ação, Sào Paulo, 7:49-59, 1984.

SILVEIRA, L.F.B. da - Thought, experimental phenomenon and experiment according to Pragmaticism. Trans/Form/Ação, Sào Paulo, 7:49-59, 1984.

ABSTRACT: The Pragmaticism of Charles Sanders Peirce, as a general theory of conception, is a theory of sign and a theory of thought. Limiting itself on the consideration of the "rational purport"' of symbols, the Pragmaticism seeks to establish the kind of causation atribuitive to thought: an efficient causation centralized in perception and experiment and a final causation determining a rational habit of conduct before the general class of experimental phenomena represented by the concept.

KEY-WORDS: Pragmaticism; thought; experimental phenomenon; experiment; semiotics; symbol; conception.

\section{REFERÊNCIAS BIBLIOGRÁFICAS}

1. BURKS, A.W. ed - Collected paper of Charles Sanders Peirce. Cambridge, Harvard Univ. Press, 1958. v.7-8.

2. GREENLEE, D. - Peirce's Concept of Sign. The Hague, Paris, Mouton, 1973.

3. HARDWICK, C.S. ed - Semiotic and Significs. Bloomongton, Indiana Univ. Press, 1977.

4. HARTSHORN, C. \& WEISS, P., eds. Collected Papers of Charles Sanders Peirce. Cambridge, the Belknap Press of Harvard Univ. Press. 1932. Reprinted 1974. v.1-6.

5. ROSENTHAL, S.B. - The pragmatic world of
Charles Peirce. Transactions the Ch. S. Peirce Society, I(1):13-22, 1983.

6. SAVAN," D. - Questions concerning certain classifications claimed for Signs. Semiotica, 19, (3/4):179-96, 1977.

7. SILVEIRA, L.F.B. da - Semiótica peirceana e produçào poética. Trans/Form/Ação, 6:13-23, 1983.

8. SHORT, T.L. - Semeiosis and Intentionality. Transactions of the C.S. Peirce Society (1981), I 73 ): 197-223, 1981.

9. WELLS, R.S. - Peirce's Notion of the Symbol. Serniotica, /9(3/4): 197-208, 1977. 